\title{
Estimates of repeatability for body weight and conformation traits in three breeds of grower pigs
}

Akporhuarho, P. O. and Obodoagwu, E.

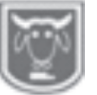

Department of Animal Science and Fisheries, Delta State University,

Faculty of Agriculture, Asaba, Delta State

Corresponding author:okpakophilip@gmail.com; +2340733960396

Abstract

The aims of the study were to provide estimate of repeatability on the body weight and body traits of the three genotype of grower pigs. Data on 30 growing pigs comprising of three strains, landrace, large white and Duroc of the same age were used to estimate the repeatability ${ }^{\circledR}$ of body weight $(B D W)$, and linear body traits measured from 2-8 weeks of growth and development. The linear body traits measured was: Head length (HDL), Body length (BDL), body girth (BDG), Ham length (HML), Ear length (ERL) and Neck circumference (NCG). Repeatability estimate for body weight of the three strains were relatively high (0.62, 0.71 and 0.64) for landrace, large white and duroc respectively at 8 weeks of growth. The repeatability values ranged from low to high for other linear body traits $(0.2-0.52)$ in the three strains of pigs at early stage of growth. The high repeatability estimates noted for most of the traits imply possible high expected genetic response from inherent transmitting ability of the pigs of traits with moderate's repeatability and the low repeatability estimates recorded for some other traits imply that collection of additional records and improvement of non-genetic factors influencing performance will improve these traits. The three genotype of pigs although were better in terms of development performance, but additional measurements and improvement of non-genetic factors influencing repeatability traits will be needed to realize expected respond from selection.

Keywords; Pigs, Body weight, Body traits, Repeatability estimates

\section{Introduction}

Selection that is due to growth traits with the hope of having superior individual with good performance has led to vigorous rapid transformation in protein supply in Nigeria. Growth and development of animal agriculture is a difficult procedure and is subject to a significant extent of genetic control. Serious and significant genetic improvements have been made by animal breeders through the use of powerful selection for specifics biological characteristics, leading to uninterrupted enhancements in body weight, meat production, growth rate, and reduction in the number of days to reach market weight in meat - type of animals (Havenstein et al., 1994b; Ilori et al., 2016). Though, with the progress of powerful genetic selection brought about reduction in the total fitness of contemporary poultry species particularly with those categorized by the otherwise desirable characteristics of quick growth and muscle deposit (Deeb and Lamont, 2001). In the advance countries like U.S.A and United Kingdom, so many domestic animals have been selected for traits of economic importance whereas the importation of exotic breeds for crossing with the local stock and rearing is the utmost prevalent practice in the developing countries like Nigeria. These exotic breeds find it very hard to utmost exhibit their worth in the tropical environment due to some adverse conditions, such as heat stress, poor nutrition, poor housing, disease problem most importantly the effect of genotype by environment interaction, consequently the need to select within our indigenous and crossbred species. Genetic 


\section{Estimates of repeatability for body weight and conformation traits}

parameter estimates in relations of genetic correction, heritability and repeatability are very beneficial apparatuses in characterizing animal agriculture. Repeatability is the amount of total phenotypic variance in several measurements of a trait attributable to eternal difference among individuals. It measures the amount of an individual's superiority or inferiority that is expected to be expressed in future measurement. That is while repeatability in used in estimating generation producing capabilities of individual animal in calculating the change performance of a population due to selection (Abdullah and Olutogun, 2006). It is used to compute the transferring capability of a stock and its capability to sustain its performance and position within a trial group on succeeding generation, conversely, the reliability of performance or behaviour over time (Hayes and Jenkins, 1997; Udeh, 2010; Ilori et al., 2016). Calculating of the breeding value of a specific animal is significance in animal breeding as it allows the husband man to define the transferring capability of individual animal for the desired traits. The use of generation averages as a support to selection for traits on which recurrent observations of phenotype can be achieved includes using estimates of repeatability to compute adjusted means suitable for linking individuals of with different number of records (Abdullah and Olutogun, 2016). The aims of this research therefore is to estimate the repeatability of growth body weight and conformation traits of three breeds of grower pigs that will help the farmers to estimate the potential of these breeds of pigs and know those breed of pigs that will be of high response to selection in any future programmed designed to improve weight in a herd.

\section{Materials and method}

\section{Location of the study}

The study was carried out at the piggery breeding unit of the Teaching and Research Farm of the Department of Animal Science, Delta State University Asaba campus. The Delta State University Asaba campus is located between latitude $60^{\circ} 14^{\prime \prime}$ and $60^{\circ}$ $49 " \mathrm{E}$, it lies in the tropical rainforest zone, characterized by seven (7) months of rainy season of between April and October, interrupted by short break in August with annual rain fall of $1500 \mathrm{~mm}-1849 \mathrm{~mm}$.

\section{Experimental animals}

Three breeds of growing pigs of equal age used for this study were purchased from a reputable farm in Eku, Ethiope East local Government area of Delta State, Nigeria at six weeks of age (16 landrace, 16 large white and 16 Duroc breed of pigs). Six weeks old grower pigs were brought to the Animal Science pavilion division of the department of Animal science, Faculty of Agriculture, Delta State University on the same day. The animals were weighed, Ear tagged and randomly assigned into three breeding groups according to breeds with two replicate each and they were designated as $\mathrm{T} 1, \mathrm{~T} 2$ and $\mathrm{T} 3$, each groups replicate had a total of eight pigs. Body weight (BW) was measured with the aid of Scout 11 electronic top loader balance $150 \mathrm{~kg}$ measuring scale thereafter, body parts were measured in centimeters with the aid of measuring tape. They were fed standard pigs diet (NRC, 1984) formulated to meet their nutrient requirements. Feed and water were given to the pigs on ad libitum, all necessary medication and vaccination programmes were carefully observed accordingly.

\section{Data collection}

Data were collected on weekly basis. Data collected were on live weight per pig and linear body measurements per pigs which 
include: Head length, Ear length, Neck circumference, Body girth, Body length and Ham length.

\section{Statistical analysis}

All data collected were analyzed using SPSS version 202016 procedure from which the analysis of variance (ANOVA) was generated to obtain the variances for estimating repeatability. Repeatability values were estimated from the variances using the technique of Becker (1984). The model used was as detailed below.

$\mathrm{X}_{\mathrm{ij}}=\mu+\mathrm{a}_{\mathrm{i}}+\Sigma_{\mathrm{ij}}$

Where:

$\mu=$ Population mean

ai_Effect of the genotype or breeding group xij = Observations made on the jth individual animal belonging to the ith genotypic group

$\Sigma \mathrm{ij}=$ The residual error due to all the observations in the experiment and their measurements.

The variance components were determined from the mean square expectation of the ANOVA and repeatability $(\mathrm{R})$ estimated using the following expression:

Where:

$$
\mathrm{R}=\frac{\delta^{\underline{2}}}{\delta_{\mathrm{B}}^{2}+\delta^{2}{ }_{W}}
$$

$\delta^{2}{ }_{\mathrm{B}}=$ Variance component due to difference among individual.

$\delta_{\mathrm{W}}^{2}=$ Within individual component of variance.
The standard error of repeatability was calculated by using the standard expression given by Becker (1984).

The standard errors of the estimates were calculated using the model as explained by Becker (1984). $\mathrm{SE}=$

$\sqrt{2}\left(1-R^{2}\left(1+(K-1) R^{2}\right) / K(K-1)(n-1\right.$

Where,

$\mathrm{K}=$ number of measurement

$\mathrm{n}=$ Number of birds

$\mathrm{r}=$ Repeatability

\section{Results and discussion}

Repeatability estimates and estimated variance components of body weight and linear body measurements in landrace, large white and Duroc grower pigs at week eight are shown in Tables 1, 2 and 3, respectively. The estimates ranged from low to medium to high. However, the majority of the growth characteristics observed had high repeatability estimates. Landraces strain had a high repeatability of 0.62 for body weight, with a medium repeatability estimates of $\mathrm{BDL}=0.52$ and $\mathrm{NCF}=0.56$ at 8 weeks of age (Table 1) growth. All the other body parts measured in this strain had low repeatability at early stage of growth, at eight weeks of age. This observation is an indication that landrace can be selected at early stage for growth traits.

Table 1: Variance components and repeatability of body parameters of landrace breed of pigs

\begin{tabular}{lllll}
\hline Body parameter & $\delta^{{ }^{2}}{ }_{\mathbf{B}}$ & $\delta^{2} \mathbf{w}$ & $\begin{array}{l}\text { Repeatability } \\
(\mathbf{R})\end{array}$ & S. Error \\
\hline BDW & 15.91 & 9.70 & 0.62 & 0.15 \\
HDL & 1.41 & 2.88 & 0.33 & 0.16 \\
EAL & 0.29 & 0.71 & 0.29 & 0.16 \\
BDL & 43.59 & 40.89 & 0.52 & 0.16 \\
NCF & 16.19 & 12.81 & 0.56 & 0.16 \\
BDG & 6.08 & 15.92 & 0.28 & 0.16 \\
HML & 3.26 & 6.29 & 0.34 & 0.17 \\
\hline
\end{tabular}

Note: that $\delta^{2}{ }_{\mathrm{W}}=$ variance within pigs, $\delta{ }^{2}{ }_{\mathrm{B}}=$ variance between pigs; $\mathrm{R}=$ Repeatability; S.E = Standard Error of Repeatability; BDW = Body weight; HDL = Head Length; BDL = Body Length; BDG = Body Girth; $\mathrm{HML}=$ Ham Length; EAL $=$ Ear Length; $\mathrm{NCF}=$ Neck Circumference. 


\section{Estimates of repeatability for body weight and conformation traits}

The results of large white (Table 2) showed that, this strain of pig had high repeatability estimates for body weight $(\mathrm{R}=0.71)$ and $\mathrm{NCF}(\mathrm{r}=0.61)$ to a medium repeatability estimates of 0.52 and 0.55 for $\mathrm{BDG}$ and BDL, respectively, measured at 8 weeks of age. Low repeatability estimates also were recorded for EAL (0.23), HDL (0.35) at early stage of growth and development, except the estimate for Ham length that was approaching a moderate estimate of 0.49 at eight weeks. Therefore, all the growth traits in this strain of grower pigs are important in selection of large white pigs except ERL (0.23) and HDL (0.35), characteristics at eight weeks of age.

Table 2: Individual and within individual components of variance and repeatabili ty of large white breed of pigs

\begin{tabular}{|c|c|c|c|c|}
\hline Body parameter & $\delta^{2}{ }_{\text {B }}$ & $\delta^{2} w$ & $\begin{array}{l}\text { Repeatability } \\
\text { (R) }\end{array}$ & S. E. \\
\hline BDW & 14.95 & 6.01 & 0.71 & 0.13 \\
\hline HDL & 1.54 & 2.77 & 0.35 & 0.17 \\
\hline EAL & 0.23 & 0.77 & 0.23 & 0.16 \\
\hline BDL & 18.48 & 52.38 & 0.55 & 0.16 \\
\hline $\mathrm{NCF}$ & 12.68 & 8.04 & 0.61 & 0.15 \\
\hline BDG & 13.35 & 12.52 & 0.52 & 0.16 \\
\hline HML & 3.23 & 3.38 & 0.49 & 0.17 \\
\hline
\end{tabular}

Note: that $\delta^{2}{ }_{\mathrm{W}}=$ variance within pigs, $\delta{ }^{2}{ }_{\mathrm{B}}=$ variance between pigs; $\mathrm{R}=$ Repeatability; $\mathrm{S} . \mathrm{E}=$ Standard Error of Repeatability; BDW = Body weight; HDL = Head Length; BDL = Body Length; BDG = Body Girth; $\mathrm{HML}=$ Ham Length; EAL = Ear Length; $\mathrm{NCF}=$ Neck Circumference.

The repeatability estimates for Duroc strain ranged from low to medium to high, at eight weeks of age. The BDW (0.64), NCF (0.61) and BDG (0.69) were all having high repeatability estimates with a recorded medium repeatable estimate of 0.53 of the body length at eight weeks of age. The estimated repeatability ( 0.32 to 0.47$)$ on every other part was having low repeatability. This is an indication that such low growth traits in Duroc have no potential to repeat their outstanding performance and maintain ranking in their successive records.

\begin{tabular}{lllll} 
Ta ble 3: Variance & components and repeatability & estimates of duroc genotype pig & \\
\hline Body parameter & $\delta^{{ }^{2}}$ & $\delta^{2}{ }_{\mathbf{w}}$ & $\begin{array}{l}\text { Repeatability } \\
(\mathbf{R})\end{array}$ & S. Error \\
\hline BDW & 15.64 & 8.71 & 0.64 & 0.15 \\
HDL & 2.37 & 3.82 & 0.38 & 0.17 \\
EAL & 0.60 & 1.29 & 0.32 & 0.16 \\
BDL & 58.05 & 51.14 & 0.53 & 0.16 \\
NCF & 18.48 & 11.81 & 0.16 & 0.15 \\
BDG & 30.44 & 13.95 & 0.69 & 0.13 \\
HML & 2.98 & 3.40 & 0.47 & 0.17
\end{tabular}

Note: that $\delta^{2}{ }_{\mathrm{W}}=$ variance within pigs, $\delta{ }^{2}{ }_{\mathrm{B}}=$ variance between pigs; $\mathrm{R}=$ Repeatability; $\mathrm{S} . \mathrm{E}=\mathrm{Standard}$ Error of Repeatability; BDW = Body weight; HDL = Head Length; BDL = Body Length; BDG = Body Girth; $\mathrm{HML}=$ Ham Length; EAL = Ear Length; $\mathrm{NCF}=$ Neck Circumference. 


\section{Akporhuarho and Obodoagwu}

Moderate repeatability estimates obtained for landrace, large white and Duroc pigs strains in this study is in agreement with the reports of Kabir et al. (2008) where moderate repeatability estimates were also reported for growth traits in Anak 2000 broiler strain. Some of the growing pig strains used in this study had lower ability to repeat their present performance in the future. Larger records are required for those with very low repeatability especially head length and ear length in Duroc, landrace and large white, body girth and ham length in landrace, strain of pigs. This is in agreement with the reports of Falconer (1989), which states that further records are required to get a high expected response from selection in traits with high repeatability estimates while those with low repeatability estimates will require large number of records. It is important to note that repeatability estimates for reproductive traits as reported by a number of studies (Ansah et al., 1983; Szwaczkowski, 2003; Bennerwitz et al., 2007) were all generally low. This could be as a result of the influence of environmental and age related factors (Falconer, 1989). In order to improve the accuracy of predicting the breeding values of the pigs, collection of additional records and improvement of non genetic factors influencing pig repeatable traits.

\section{Conclusion}

It was concluded that the repeatability estimates obtained from body weight and other body parameters of the 3 genotypes of pigs were high to moderate to low. However, those of high to medium estimates are important in selection programmes. Therefore, it is recommended that collection of additional records and improvement of non genetic factors influencing repeatable traits in pigs will improve the accuracy of predicting the inherent transmitting ability of pigs having these traits.

\section{References}

Abdullah, A. R. and Olutogun, O 2006. Estimates of genetic and phenotypic parameters for preweaning growth traits of N'Dama (Bos Taurus) Calves in the humid tropics of Nigeria. Liv. Res. Rur. Der., 18(8).

Ansah, G. A., Segura, J. C. and Buckland, R. B. 1983. Semen production, sperm quality and their heritability as influenced by selection for fertility of frozen $\mathrm{t} \mathrm{h}$ a $\mathrm{w}$ e d $\mathrm{s}$ e $\mathrm{m}$ e $\mathrm{n}$ i $\mathrm{n}$ chicken.Poult.Sci., 64:1801-1803.

Becker, W. A. 1984. Manual of procedure in Quantitative Genetics, $3^{\text {rd }}$ Edition. Washington State University.

Bennerwitz, J. O., Morgades, O. Preisinger, R. Thalerand, G. and Kalm, E. 2007. Variance components and breeding value estimation for reproductive traits in laying hens usinga Bayesian threshold model. Poult. Sci., 86:823-828.

Deeb, N. and Lamont, S. J. 2001. Genetic Architecture of growth and body composition in Unique chicken population. J. Hered., 93(2): 107118.

Falconer, D. S. 1989. Introduction to quantitative genetics. $2^{\text {nd }}$ Edn., London. Inc.

Havensterin, G. B., Farket, P. R., Scheideler, S. E. and River, D. V. 1994. Carcass composition and yield of 1991 vs 1957 meat-type chickens when feed "typicals 1957 and 1991 broiler diets. Poult. Sci., 73: 1795-1804.

Hayes, P. P. and Jenkins, S. H. 1997. Individual Variation in Mammals. 
J. Mammal., 78:274-293.

Illori, B. M., Akano, K., Durosaro, S. O., Adebambo, A. O. and Ozoje, M. O. 2016. Estimate of repeatability for growth traits of pure and crossbreed turkeys in the tropics. Nigeria Journal of Animal Production-43: (1):27-36.

Kabir, M., Yakubu, H., Akpa, G. N., Jokthan, G. E., Abdu, S. B., Abdulrashid, $M$. and Adamu, Y. H. 2008. Estimates of repeatability for body weight and body conformation traits in Anak (2000) strain of broiler chickens. Proceedings of the $13^{\text {th }}$ Annual Conference of Animal Science Association of Nigeria. Pp.18-21.
N R C 2012. Nutrient Requirements of Swine, Animal nutrient series, National Academics press, Washington, D C.

Szwaczkowski, T. 2003. Use of mixed model methodology in poultry breeding. Estimation of genetic parameters. In poultry genetics, breeding and biotech by Muir, W. $\mathrm{M}$ and Aggrey, S.E. Ed CAB Int. Walling ferd, UK., pp:165-201.

Ude, I. 2010. Repeatability of egg number and egg weight in two strains of layer type chicken. Int. J. Poult. Sci. 9 (7): 675-677.

Received: $17^{\text {th }}$ August, 2019 Accepted: $27^{\text {th }}$ January, 2020 